\title{
Introducing Idioms in Foreign Language Class for Students of Translation Studies Departments of Kazakhstani Higher Institutions
}

\author{
Anar Baizhanova \\ MA, Senior Lecturer, KazGUU University, Astana, Kazakhstan \\ anarbah@mail.ru \\ Aknur Toleubayeva \\ MA, Senior Lecturer, KazGUU University, Astana, Kazakhstan \\ aknur.87@mail.ru \\ Gulnar Muratova
}

PhD, Professor, Gumilyov Eurasian National University, Astana, Kazakhstan muratova_ga@enu.kz

\section{Doi:10.5901/mjss.2015.v6n3s2p421}

Abstract

The given article is devoted to considering the problem of using idioms in foreign language class for students of translation studies departments of Kazakhstani higher institutions. The authors analyse the current situation with teaching foreign languages for students of translation studies speciality and describe their experiment demonstrating the increase in the level of students' motivation to learn a foreign language after introducing idioms in the class. In addition, they show the significance of mastering idioms for future translators / interpreters.

Keywords: translation / interpreting teaching, foreign language teaching, motivation, idiom, idiomatology

\section{Introduction}

While teaching translation / interpreting for students of Translation Studies Department of the Kazakh University of the Humanities and Law we have defined translating idioms as one of the main difficulties. That's why we have devoted to this theme our project conducted during our three-month scientific internship in the Netherlands.

The given article is aimed to describe the process of the experiment in the Netherlands and perspectives of implementing its results in our home institution.

First and foremost, we intended to find Dutch organizations which could be helpful in implementing our experiment [linguistic departments of a higher institution, language centres] and to interview them to get an idea of the situation with using idioms and having a separate subject devoted to this aspect of language in the Dutch educational institutions.

Then we conducted an experiment with a group of our colleagues from Kazakhstan whose level of English needed to be improved. We measured their level of motivation before and after the experiment to find out effectiveness of the suggested project. The results of the experiment are to be introduced to the authorities and teaching staff of the Translation Studies Department of Kazakh University of the Humanities and Law.

Actuality:

The topic is connected with one of educational priorities described in the OECD document under the heading "Internationalization" where special significance is attributed to knowledge of English for all graduates of Kazakhstani universities. But learning a foreign language without language environment can be challenging for many people, and they often give it up. As a result, a considerable part of graduates of Kazakhstani higher institutions do not speak English or speak it at a low level. That's why increasing students' level of motivation becomes of great importance to teachers of English all over Kazakhstan. And using idioms in foreign language class can make students get interested not only in the outcome, but also in the process of learning the language. In addition, mastering idioms of the studied language gives future translators / interpreters an opportunity to improve their professional level.

Goal: to increase the level of motivation of students (of the Translation Studies of the Kazakh University of the Humanities and Law in particular) to learn foreign languages (the English language in particular) by introducing idioms in the foreign language class and to improve their translation / interpreting skills. 


\subsection{Objectives}

1) to analyse the experience of colleagues from Dutch higher institutions in using idioms in the foreign language class;

2) to prove that introducing idioms in foreign language class can help to increase students' interest in learning the English language;

3) to implement the results of the investigation in practice of teaching the English language in higher institutions of Kazakhstan;

4) to show that mastering idioms of the studied language improves translation / interpreting skills of students.

\subsection{Stakeholders}

1) authorities of Translations Studies Department of the Kazakh University of the Humanities and Law;

2) teaching staff of Translations Studies Department of the Kazakh University of the Humanities and Law;

3) students of Translations Studies Department of the Kazakh University of the Humanities and Law.

\subsection{Dutch counterparts}

1) Hilde Vonk, a teacher of English at Leiden University Language Centre

2) Annemiek Wegman, a teacher of English at Rotterdam Language Centre

\section{Description}

\subsection{SWOT analysis}

\subsubsection{Strong points}

1) we have an experimental group and an adviser at our disposal;

2) measuring the level of motivation is based on self-designed test;

3) we and our colleagues will be able to enrich our vocabulary with idiomatic expressions of the English language;

4) we and our colleagues will be able to get familiar with some cultural peculiarities through learning idioms;

5) scientific researches of students can be based on the knowledge they get in the course of learning idiomatology;

6) there will be less difficulties with translating idioms for students of translation studies departments of Kazakhstani higher institutions.

\subsubsection{Weak points}

1) it will be challenging to choose idioms according to the themes given in the syllabus;

2) it will cost effort also for teaching staff to familiarize themselves with idiomatic vocabulary.

\subsubsection{Opportunities}

1) enriching our own vocabulary and vocabulary of our colleagues with idiomatic expressions of the English language;

2) developing speaking skills on the basis of introduction of idioms;

3) improving translation / interpreting skills of students of the given speciality;

4) using the experiment outcomes in higher institutions and even in secondary schools of Kazakhstan.

\subsubsection{Threats}

1) obtaining results of the project can take longer time than we have expected (we may not have enough time to achieve our goals in the Netherlands); 
2) we can face resistance of the authorities as well as teaching staff.

\subsubsection{Step-by-step actions}

1) to find a Dutch organization [linguistic department of a higher institution, language centre] which could be helpful in implementing the experiment two organizations were chosen
a) Leiden University Language Centre
b) Rotterdam Language Centre

2) to make a questionnaire for the Dutch organization: before taking interviews we have designed a questionnaire

a) In which way are the subjects [core and elective courses] financed in your institution?

b) Who are curricula used in your institution designed by?

c) Who are these curricula approved by?

d) How much time do you need to approve the curriculum in your institution?

e) Are they compulsory or elective?

f) In which way are elective courses made attractive for students?

g) Which subjects connected with idiomatology do you have in your curriculum?

h) How much time is devoted to this aspect of linguistics?

i) How is this aspect of linguistics reflected in the summative assessment?

j) Which types of formative assessment do you usually implement during the course of idiomatology?

k) How many students do you usually have in your groups in a language class?

l) Which measures do you take to motivate your students?

m) In which teaching format do you usually work in a language class?

n) Have you ever tried to measure the level of motivation of your students?

o) If yes, which tests did you use to define the level motivation?

p) Have you ever questioned your students to find out the aspect of language which is the most important I interesting for them?

q) Do you usually use course assessment questionnaire after or during the course?

3) to visit the Dutch organization in order to explore the situation in Dutch institutions two interviews were taken:

a) with Hilde Vonk, a teacher of English at Rotterdam Language Centre

b) with Annemiek Wegman, a teacher of English at Rotterdam Language Centre

4) to measure the level of motivation in the experimental group:

a) a test on measuring the level of motivation was designed

b) the test was suggested to our colleagues from different departments of Kazakhstani higher institutions as an experimental group

Before the experiment

\begin{tabular}{|c|l|l|l|l|l|}
\hline & I learn foreign languages, because ... & Agree & Rather agree & Rather don't agree & Don't agree \\
\hline 1 & this is what my parents want & & & & \\
\hline 2 & I need it in my future profession & & & & \\
\hline 3 & I want to work / live abroad (English-speaking country) & & & & \\
\hline 4 & it is prestigious & & & & \\
\hline 5 & $\begin{array}{l}\text { I want to be a good teacher / interpreter / translator of foreign } \\
\text { languages }\end{array}$ & & & & \\
\hline 6 & I need it for another profession & & & & \\
\hline 7 & $\begin{array}{l}\text { it is required in our country to speak several languages (at } \\
\text { least three) }\end{array}$ & & & & \\
\hline 8 & it enables me to expand my world view & & & & \\
\hline 9 & I do it for fun / I find speaking different languages exciting & & & & \\
\hline 10 & my friend is learning a foreign language & & & \\
\hline 11 & I want to travel to different countries & & & \\
\hline 12 & $\begin{array}{l}\text { I want to understand culture and life-style of people from } \\
\text { different countries better }\end{array}$ & & & & \\
\hline 13 & other reasons (write down your own reasons) & & & \\
\hline
\end{tabular}


5) to find out how familiar the experimental group is with idioms of the English language: general knowledge of idioms of students of the experimental group was checked by presenting a placement idiom test

\section{Match Two Parts of Idioms!}

$\begin{array}{cccc}1 & \text { to smell } & \text { a } & \text { someone's leg } \\ 2 & \text { a pain } & \text { b } & \text { an arm and a leg } \\ 3 & \text { to cost } & \text { McCoy } \\ 4 & \text { to keep up } & \text { c } & \text { like a dog } \\ 5 & \text { as blind } & \text { d } & \text { a rat } \\ 6 & \text { to pull } & \text { e } & \text { eye to eye } \\ 7 & \text { the real } & \text { f } & \text { as a bat } \\ 8 & \text { to talk } & \text { g } & \text { in the family } \\ 9 & \text { a wise } & \text { h } & \text { like a horse } \\ 10 & \text { to work } & \text { i } & \text { in the neck } \\ 11 & \text { to run } & \text { j } & \text { of all trades } \\ 12 & \text { to see } & \text { I } & \text { or Harry } \\ 13 & \text { a jack } & \text { m } & \text { guy } \\ 14 & \text { to eat } & \mathrm{n} & \text { with the Joneses } \\ 15 & \text { Tom, Dick, } & 0 & \text { turkey }\end{array}$

\section{Write Down the Definitions of Idioms from the First Task!}

\subsection{Choose the correct variant!}

1. If you're too chicken to try skydiving, you
a. enjoy it very much.
b. afraid of trying it.
c. think it's too expensive for you.

2. If you should shake a leg, it means you should
a. dance.
b. kick someone.
c. hurry up.

3. A man of means is
a. poor.
b. rich.
c. educated.

4. A bookworm is someone who
a. loves to read.
b. hates books.
c. destroys books.

5. Someone who goes Dutch
a. goes shopping.
b. pays their own bill.
c. gets fat.

6. "A big mouth" means
a. smb., who can't keep secrets.
b. smb., who likes singing.
c. smb., who likes shouting.

7. A copycat
a. is intelligent and reads a lot.
b. likes milk and is lazy.
c. does the same things as other people.

8. Someone who is pigheaded

a. is fat and eats a lot. 
b. doesn't take advice from others.

c. never works and is dirty.

9. "Nosey" means
a. hard-working.
b. very curious.
c. very nice.

10. If we have a sweet tooth, we
a. have a toothache.
b. flatter a lot.
c. like sweets very much.

\section{Fill in the Gaps Using an Appropriate Idiom from you List!}

1. -Why didn't you buy this dress? -Because I have no money. It ...!

2. We're afraid of our father, so when he comes home, we sit ...!

3. You can always see him jogging at 5 a.m. He's an ... .

4. She's found a job as a .... at the local studio, because she wants to do a lot of different things.

5. Your task was to learn it ...! You should know every word in this text!

6. She's been walking round with ... because she has broken up with her boy-friend.

7. She always buys the same expensive dresses as her neighbours, even if she doesn't have enough money, because she doesn't want to be worse than others. So she always ... .

8. Liz won't listen to me! She always does everything in her own way. She is so .... .

9. He can't see anything, he's ...

10. Memorizing all these dates, scientists and classifications is ... for me! It's so annoying!

6) to use different activities with idioms in the English language class

different activities with using idioms in the English language were carried out with the experimental group:

a) at the first stage of the experiment (doing various tasks without introducing idiomatic expressions)

Exercise 1: Match animals with the pictures

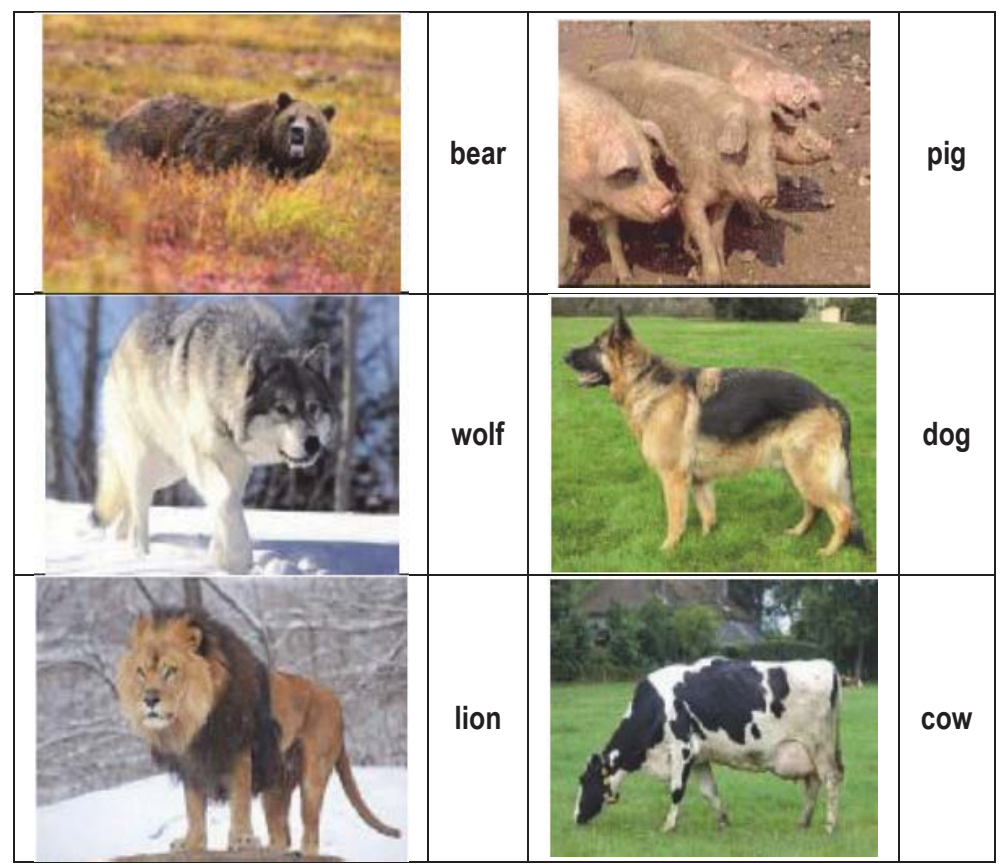


Exercise 2: Match animals with their Russian equivalents

\begin{tabular}{|c|c|c|c|}
\hline bear & медведь & pig & свинья \\
\hline wolf & волк & dog & собака \\
\hline lion & лев & cow & корова \\
\hline
\end{tabular}

Exercise 3: Fill in the gaps with the appropriate name of an animal

1) ... is a large, heavy, mammal that walks on the soles of its feet, with thick fur and a very short tail.

2) ... is a fully grown female animal of a domesticated breed of ox, used as a source of milk or beef.

3) ... is a large tawny-colored cat that lives in prides, found in Africa and northwestern India.

4) ... a domesticated carnivorous mammal that typically has a long snout, an acute sense of smell, and a barking, howling, or whining voice.

5) ... a wild carnivorous mammal that is the largest member of the dog family, living and hunting in packs.

6) ... an omnivorous domesticated hoofed mammal with sparse bristly hair and a flat snout for rooting in the soil, kept for its meat.

Exercise 4: Build up six sentences containing the names of the animals given above

b) at the second stage of the experiment (doing various tasks with introducing idiomatic expressions

Exercise 1: Match pictures with idioms and their definitions / explanations

\begin{tabular}{|l|l|l|}
\hline & a copycat & a person who does the same things as other people do \\
\hline
\end{tabular}

Exercise 2: Match idioms with their Russian equivalents

\begin{tabular}{|l|l|l|l|}
\hline early bird & ранняя пташка & pig-headed & упрямый как осёл \\
\hline a copycat & обезьяна & to work like a dog & работать как вол \\
\hline
\end{tabular}


Exercise 3: Fill in the gaps with the appropriate idioms

1) Anna always wears the same clothes as her friends. She is such a ...

2) James goes to school and then works two evening jobs. He ...

3) You always get up at seven in the morning. You are a real ...

4) He never takes advice from anyone. He is just ...

Exercise 4: Describe a person using the idioms given above. Discuss the differences between the images created in English and in Russian idioms for expressing the same meaning.

7) to measure the level of motivation afterwards

after the second stage of the experiment the level of motivation of the experimental group was measured once again

a) After the first stage of the experiment

1. Which exercises did you like most of all?

\section{$\begin{array}{llll}1 & 2 & 3 & 4\end{array}$}

2. Which exercises do you find the most effective?

a) for language acquisition

$$
\begin{array}{llll}
1 & 2 & 3 & 4
\end{array}
$$

b) memorizing technique

$$
\begin{array}{llll}
1 & 2 & 3 & 4
\end{array}
$$

3. Graduate the given exercises according to the degree of complexity.

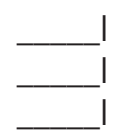

4. Which exercises motivate you to learn the English language more?
a) the easier ones 0
b) the more difficult ones 0

b) After the second stage of the experiment

1. Which exercises did you like most of all?

\section{$\begin{array}{llll}1 & 2 & 3 & 4\end{array}$}

2. Which exercises do you find the most effective?

a) for language acquisition

\section{$\begin{array}{llll}1 & 2 & 3 & 4\end{array}$}

b) memorizing technique

\section{$\begin{array}{llll}1 & 2 & 3 & 4\end{array}$}


3. Graduate the given exercises according to the degree of complexity.

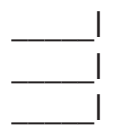

4. Which exercises motivate you to learn the English language more?

a) the easier ones 0

b) the more difficult ones 0

5. Which forms of work motivate you most of all?
a) frontal work 0
b) individual work o
c) work in pairs 0
d) work in groups 0
e) work in plenum $\circ$

6. What attracted your attention in the second stage of the experiment?

7. Which function do idioms have in the speech, in your opinion?

\begin{tabular}{|c|l|l|l|l|}
\hline By using idioms you make your speech more ... & agree & rather agree & rather don't agree & don't agree \\
\hline informative & & & & \\
\hline emotional / expressive & & & & \\
\hline culture-specific & & & & \\
\hline meaningful & & & & \\
\hline argumentative & & & & \\
\hline authentic & & & \\
\hline
\end{tabular}

8. What can increase the level of your motivation to learn a foreign language?

9. Which strategies to increase the level of motivation can you personally suggest?

10. Which idioms were the most interesting for you? Why?

11. Is there any new information you have learnt about the culture after the experiment?

8) to introduce the project to the authorities and teaching staff of Translation Studies Department of Kazakh University of the Humanities and Law

a) the results of investigation are to be presented for the authorities of Translation Studies Department of Kazakh University of the Humanities and Law

b) a workshop for teaching staff of Translation Studies Department of Kazakh University of the Humanities and Law giving an idea of the project and its aims is to be held

9) to implement the result of the project with teaching staff and students of Kazakh University of the Humanities and Law

a) the level of students' motivation is to be measured in the beginning of the project

b) different activities with using idioms are to be introduced in the English language class

c) the level of students' motivation is to be measured afterwards

d) a special course "Phraseology of the Modern English Language" is to be designed and taught

e) different activities with translating texts containing idiomatic vocabulary of the English language are to be suggested

\section{Recommendations}

1. For authorities of the Translation Studies Department of the Kazakh University of the Humanities and Law to make changes in the curriculum, i.e. to add an elective course "Phraseology of the Modern English Language": 
We need to explain to the authorities the relevance of this course for increasing students' level of motivation to learn the English language and for improving their translation / interpreting skills. That's why it is necessary to write down a convincing substantiation report proving correctness of the idea by using the results of the work on the project conducted in the Netherlands. In addition, it is important to introduce a good syllabus of the course to the authorities.

2. For teaching staff of the Translation Studies Department of the Kazakh University of the Humanities and Law

to conduct the described experiment with their students to find out if the level of students' motivation has increased after the experiment:

We need to convince the department's teaching staff of the importance of conducting the experiment, suggest them the test for measuring the level of students' motivation and different activities with using idioms. Moreover, it is necessary to show teachers the significance of mastering idiomatic vocabulary of the English language for developing translation / interpreting skills of students of Translation Studies Department.

3. For students of the Translation Studies Department of the Kazakh University of the Humanities and Law

to make a project connected with idioms:

We want to suggest our students preparing a project connected with idioms of the English language as the final assignment. It is important to explain to them the aim of the assignment consisting in consolidation of their knowledge of idiomatic vocabulary of the English language and in development of their research and translation / interpreting skills.

Possible variants: a roundtable, a scientific research (course paper, article), a film / video, a game, etc.

\section{Conclusion}

Every teacher is in search of effective methods of raising the level of motivation of their students. Introducing idiomatic lexical units connected with some particular themes to the students of Translation Studies department of Kazakh University of the Humanities and Law we noticed their increased interest in working with new vocabulary. We decided to check if systematic introduction of idioms in the foreign language class would bring the same effect and prepared necessary materials for the experiment. The training program in the Netherlands gave us an additional opportunity to collect them.

Although a number of investigations have been devoted to the problem of mastering idiomatic vocabulary of a foreign language and translating texts containing idiomatic lexical units it is still remaining actual for it is still causing difficulties for many translators / interpreters.

We have suggested the described project as one of the ways to solve the problem. We have compared the situations with teaching foreign languages and translation / interpreting in the Netherlands and in Kazakhstan and have come to a conclusion that it is worth using the experience of the Dutch colleagues in our teaching practice.

The experiment is based on the needs of students and teaching staff of Translation Studies department of Kazakh University of the Humanities and Law, but we are sure that the results of the investigation can be implemented in any translation studies department of a Kazakhstani higher institution or even a specialized linguistic secondary school.

\section{References}

Fanny Meunier, Sylviane Granger. «Phraseology in Foreign Language Learning and Teaching». Amsterdam-Philadelphia: John Benjamins B.V., 2008

Broukal M. «ldioms for Everday Use». Lincolnwood (Chicago): National Textbook Company, 2003

Cowie A.P. «Phraseology: Theory, Analysis and Applications». Oxford: Clarendon Press, 1998

Skandera P. «Phraseology and culture in English». Berlin, New-York: Mouton de Gruyter, 2007 